\title{
¿POR QUÉ ES NECESARIO QUE NUESTROS HIJOS ESTUDIEN EN UNA INSTITUCIÓN EDUCATIVA ADVENTISTA?
}

Saludo: Es grato estar ante ustedes y exponer lo que señala la Palabra de Dios. El Espiritu Santo está con nosotros y sabemos que Él nos iluminará para interpretar correctamente la Escritura. Oremos. Texto clave: "Y él me dijo: Es necesario que profetices otra vez sobre muchos pueblos, naciones, lenguas y reyes" (Ap 10:11).

Proposición: Nuestros hijos, en las Instituciones Educativas Adventistas, son preparados para cumplir la misión profética del adventismo, para salir vencedores de la crisis final y para morar con Cristo por la eternidad.

Pensamiento clave: En el tiempo del fin, la Educación Adventista es uno de los mejores instrumentos divinos para preparar a niños y adolescentes para el segundo retorno del Señor Jesucristo.

\section{Un gran desafío para los padres adventistas: un cristianismo pluralista}

\section{Ilustración}

En una ocasión, un hermano vino a buscarme. Estaba confundido y preocupado, porque su hijo estaba cada día más secularizado y le abordaba con muchas preguntas. Entre tales preguntas, estaba: “Dios realmente existe? ¿Cuán- 
to tiempo tiene el planeta tierra, millones de años? ¿Cuál es el problema que uno, como adventista, deje de asistir al templo los sábados? ¿Qué problema hay que uno experimente el sexo antes del matrimonio?".

Aquel padre estaba mortificado. Su hijo, día a día, dejaba de relacionarse con Cristo. Ahora, el menor dudaba de la existencia, el amor y la justicia de Dios.

Hace unos días, aquel padre me escribió a mi correo, diciéndome: "ore por mi hijo. Se retiró totalmente de la iglesia".

¿Cuál fue el problema principal de esta situación? ¿Cuántos de los padres presentes no experimentaron algo similar? ¿Realmente, es un desafío que nuestros hijos asistan a una institución no adventista?

1. El cristianismo, actualmente, está pasando por una crisis nunca antes imaginada. La vasta mayoría de religiones cristianas han negado las verdades bíblicas y están tomando estilos de vida seculares. Aunque parezca increíble, no se está practicando el principio de Sola Escritura, y se está enseñando creencias antibíblicas. Entre ellas, están:
a. El rapto secreto.
b. El alma es inmortal.
c. Una vez salvo, salvo para siempre.
d. La predestinación dual. La salvación de unos es única- mente por la elección divina, en un principio.
e. La salvación se obtiene gracias a la práctica de ritos.
f. Dios desea que se repose el día domingo.
g. Los diez mandamientos fueron abolidos en la cruz.
h. El juicio no es bíblico. 
i. El santuario es simplemente una metáfora, no un lugar real.

j. La obediencia no es parte de la salvación. En su salvación, el hijo de Dios solo contribuye con su pecado.

k. Dios utilizó la evolución como método de creación, etc.

1. El evolucionismo.

m. La adoración a María y a los "santos", etc.

2. Estas enseñanzas han influido en el estilo de vida de muchos cristianos. Por ejemplo, alguien no adventista, en una oportunidad, me dijo: "mi esposo, que tiene 15 años como bautizado, continúa emborrachándose. Pienso que cuando Cristo lo llegue a raptar -creencia que ella tenía-, lo llevará al cielo aun estando ebrio. Por una sencilla razón: una vez salvo, salvo para siempre”. Si analizamos esta idea, podemos percibir que la comprensión bíblica de la salvación influye en el estilo de vida del creyente. Si alguien interpreta erróneamente la salvación, vivirá de manera incorrecta el cristianismo.

3. Precisamente, esta comprensión errada de la Escritura abunda en el cristianismo, y lo único que ha producido ha sido un mal testimonio delante de religiones no cristianas (budistas, musulmanes, etc.). ¡El cristianismo está más secularizado que nunca! Es diferente el estilo de vida cristiano contemporáneo al de la iglesia apostólica del primer siglo.

4. Lo preocupante es que estas interpretaciones incorrectas de la Biblia son enseñadas y promovidas en los sistemas educativos católicos y los evangélicos. Esto ha permitido la existencia de más alternativas al momento de elegir la institución educativa que deseamos para nuestros hijos. 
Entre ellas están:

a. Escuelas/colegios/universidades seculares (no cristianas).

b. Escuelas/colegios/universidades cristianas, pero no adventistas.

c. Escuelas/colegios/universidades adventistas.

5. Por supuesto, muchos no pensarían que la mejor opción es la primera (aunque hay casos). Sin embargo, hay varios padres adventistas que prefieren instituciones cristianas no adventistas que las mismas adventistas, ya sean escuelas, colegios y universidades. ¿La causa? Entre otras, piensan que porque son cristianas, todas se fundamentan en la Biblia. Como ya se mencionó, esta idea está muy lejos de la realidad.

6. Entonces, si un padre envía a su hijo a una institución secular, le estaría guiando al ateísmo y al evolucionismo; salvo que tenga tanta fe como la de Daniel en Babilonia. Si aquel menor es matriculado en una institución católica o evangélica, se lo estaría colocando en un lugar donde no se respeta lo que dice la Escritura ni se promueve el estilo de vida bíblico. Entonces ¿Cuál sería la mejor alternativa? Puesto que es bíblico, el mejor sistema educativo es el adventista (este merece un estudio aparte).

7. Nadie puede negar la unión de "iglesia y educación"; en muchas religiones se la reconoce. Estos sistemas educativos solo son medios para lograr un fin: enseñar y promover lo que cada religión profesa. ¿Mediante qué? Por medio del estilo de vida de cada devoto profesor, de sus 
enseñanzas y del curso de Religión (sin descartar las prácticas diarias en el aula, los cultos, los retiros espirituales, los campamentos, etc.). Al final, el alumno será influenciado, de cualquier manera y hasta involuntariamente, por la fe que profesa la institución.

8. Por ello, cada padre adventista necesita velar por el conocimiento bíblico y por el estilo de vida de su menor hijo. Debe considerar el gran consejo del apóstol Pablo:

"Ten cuidado de ti mismo y de la doctrina; persiste en ello, pues haciendo esto, te salvarás a ti mismo y a los que te oyeren”. (1 Ti 4:16)

9. Con un Sistema Educativo no bíblico, ¿nuestros hijos persistirán en la sana doctrina, experimentarán la salvación en Cristo y cumplirán la misión que Dios les encomendó?

\section{La visión apocalíptica/profética de la Educa- ción Adventista}

\section{Ilustración}

Clifford Goldstein, a quien se le dice de cariño "Cliff", era un joven que no apreciaba mucho a los cristianos ni abrazaba el cristianismo. Además de tener sangre judía, él era escritor y ateo. Generalmente, él acostumbraba avergonzar a los predicadores cristianos en la Universidad. No necesariamente era tolerante.

Hasta que llegó a sus manos un libro que le cambiaría la vida: El gran conflicto, escrito por Elena G. de White. A través de esta literatura, él decidió entregar su vida a Cristo. Aquel jo- 
ven apologista que -valga la redundancia- defendía a capa y espada el ateísmo, terminó humillándose ante Dios. Ahora, se convertiría en uno de los más grandes apologistas adventistas. Actualmente, él es el director general de la Lección de Escuela Sabática del adventismo mundial; y le agrada repartir libros de El gran conflicto en la casa blanca de los Estados Unidos.

Interesante conversión ¿verdad? Es interesante notar que el mensaje profético es capaz de convertir hasta los corazones más duros. ¿Qué tal si este rol apocalíptico lo cumplimos en las Instituciones Educativas Adventistas? ¿Existe alguna relación entre la "apocalíptica bíblica" y la "Educación Adventista"?

1. ¿En qué consiste la "visión profética/apocalíptica" del adventismo? Esta visión trata sobre la identidad, misión y mensaje proféticos de la Iglesia Adventista del Séptimo Día, cuyo fundamento son las profecías bíblicas reveladas en Daniel y Apocalipsis, y en la doctrina del Santuario. ${ }^{1}$ Esta visión tiene el propósito de preparar a los habitantes de la tierra para la segunda venida de Cristo y, para cumplirlo, se ha de proclamar los mensajes de los tres ángeles de Apocalipsis 14:6-12. ¿Cuáles son estos tres mensajes?

Primer mensaje: "Vi volar por en medio del cielo a otro ángel, que tenía el evangelio eterno para predicarlo a los moradores de la tierra, a toda nación, tribu, lengua y pueblo, diciendo a gran voz: Temed a Dios, y dadle gloria, porque la hora de su juicio ha llegado; y adorad a aquel que hizo el cielo y la tierra, el mar y las fuentes de las aguas".

${ }^{1}$ La unidad literaria de estos dos libros se la conoce como Apocalíptica bíblica. 
Segundo mensaje: "Ha caído, ha caído Babilonia, la gran ciudad, porque ha hecho beber a todas las naciones del vino del furor de su fornicación".

Tercer mensaje: "Y el tercer ángel los siguió, diciendo a gran voz: Si alguno adora a la bestia y a su imagen, y recibe la marca en su frente o en su mano, él también beberá del vino de la ira de Dios, que ha sido vaciado puro en el cáliz de su ira; y será atormentado con fuego y azufre delante de los santos ángeles y del Cordero; y el humo de su tormento sube por los siglos de los siglos. Y no tienen reposo de día ni de noche los que adoran a la bestia y a su imagen, ni nadie que reciba la marca de su nombre. Aquí está la paciencia de los santos, los que guardan los mandamientos de Dios y la fe de Jesús".

2. Este triple mensaje es relevante en el tiempo del fin, porque permite conocer a Dios, guía a la salvación en Cristo a los habitantes de la tierra y registra verdades bíblicas que desenmascaran las doctrinas falsas que enseña Babilonia. Estas verdades, extraídas de Apocalipsis 14:6-12, son las siguientes:
a. El evangelio eterno
b. La santificación
c. La creación
d. El juicio pre-advenimiento y la segunda venida de Cristo
e. La caída de Babilonia
f. La marca de la bestia y el sello de Dios
g. Los diez mandamientos
h. El testimonio de Jesucristo
i. El santuario. ${ }^{2}$

${ }^{2}$ Para un mayor estudio sobre estas verdades básicas, no únicas, ver, 
3. Las enseñanzas falsas, que hoy en día gran parte del cristianismo sostiene y enseña, son contrarias a las verdades bíblicas que registra Apocalipsis 14. Mientras Babilonia pervierte a las naciones con "el vino del furor de su fornicación”, el pueblo de Dios del tiempo del fin, simbolizado por estos "tres ángeles", guía a la adoración verdadera porque tiene una profesión de fe y un estilo de vida fundamentados en la Escritura.

4. Entonces, ¿qué tienen que ver los Mensajes de los tres ángeles con la Educación Adventista? Mucho. El sistema educativo adventista llegó a existir con un solo propósito: ser un instrumento para la proclamación de los Mensajes de los tres ángeles. La Educación Adventista le debe su existencia y dinamismo al mensaje profético adventista. La razón de ser de la Educación Adventista es la apocalíptica bíblica. Según el historiador George Knight: "tanto el nacimiento como el desarrollo de la educación adventista fueron estimulados por la energía explosiva de la misión apocalíptica”. Más adelante, él señala: "No es demasiado enfatizar que fueron las necesidades de la misión apocalíptica a toda nación, pueblo y lengua lo que dio energía a los comienzos de la Educación Adventista en la década de $1870{ }^{3}{ }^{3}$

5. En síntesis, el sistema educativo adventista tiene una visión profética, y es uno de los instrumentos para proclamar el evangelio eterno.

Oscar Mendoza Orbegoso, "El mensaje del remanente en el tiempo del fin: El mensaje de los tres ángeles de Apocalipsis 14:6-12- Partes I y II", Estrategias 6, no. 2 (2009): 77-86 y Estrategias 7, no. 1 (2010): 59-78.

3"La educación adventista y la visión apocalíptica- parte I", Revista de Educación Adventista 27 (2008): 8. Es interesante notar que, a partir de esa década, la Educación Adventista, con la visión profética, llegó a crecer considerablemente tanto en número de instituciones como en alumnos. 


\section{El propósito de la Educación Adventista}

\section{Ilustración}

Hace tres años, un estudiante me preguntó: “Pastor, cuál es el objetivo principal de una institución adventista, únicamente preparar alumnos para que ingresen a las universidades más prestigiosas? Le digo esto porque hoy, mi profesor de Física nos dijo eso en clase".

"No" -le respondí-. "Nuestra meta principal es formar discípulos de Cristo para prepararlos para la segunda venida de Cristo y, por supuesto, para que proclamen los mensajes de los tres ángeles”.

Gracias a Dios, a él y a su familia les dimos estudios bíblicos semanalmente. Ahora, Fernando es un gran diácono y líder en una de las principales iglesias de Lima.

La Educación Adventista tiene dos objetivos principales: (1) Preparar a los alumnos para la crisis final y la segunda venida de Cristo, y (2) Preparar misioneros para la proclamación de los Mensajes de los tres ángeles.

1. Preparar a los alumnos para la crisis final y la segunda venida de Cristo. El pastor Shane Anderson, en su libro How to Kill Adventist Education, indica que uno de los propósitos de nuestras instituciones es "hacer seguidores de Cristo completamente devotos, que ayuden a otros a resistir bíblicamente el engaño final". ${ }^{4}$ Como la Educación Adventista no solo piensa en el presente sino también en el futuro, su

${ }^{4}$ Shane Anderson, How to Kill Adventist Education (and How to Give It a Fighting Chance!) (Hagerstown, MD: Review and Herald, 2009), 44. 
objetivo principal es preparar verdaderos adoradores para la última crisis (cf. Dn 12:1-2).

Parte de la misión educativa adventista es guiar a los estudiantes a los pies de Cristo; para que cuando Él retorne, cada alumno lo reciba como Rey y Señor del universo. La meta principal, una vez más, es educar para esta vida y para la eternidad.

2. Preparar misioneros para proclamar los Mensajes de los tres ángeles. Este sistema nace con el propósito de formar misioneros de la verdad presente, discípulos de Cristo en acción, con el fin de que ellos proclamen la verdad presente a toda nación, tribu y lengua. Según Knight: "Las escuelas secundarias y los colegios superiores se desarrollaron alrededor del mundo para preparar misioneros que ayudaran a proclamar el mensaje apocalíptico de Apocalipsis 14".5

Por medio de la Educación Adventista, cada hijo (a), en primer lugar, conocerá al Cristo verdadero que revela la Biblia, y no al Cristo que muchos han distorsionado. En segundo lugar, cada uno de ellos llegará a ser formado como discípulo y misionero de Cristo, teniendo como función proclamar los Mensajes de los tres ángeles. En tercer lugar, cada alumno conocerá y vivirá en la verdad, teniendo una profesión de fe y un estilo de vida bíblicos. En último lugar, cada estudiante será preparado para la crisis final y así estar listos para permanecer en pie cuando Cristo regrese por segunda vez, y morar con Él por la eternidad.

Nuestros hijos necesitan estudiar en instituciones educativas adventistas. No existe otra alternativa mejor. Solo es cuestión de hacer la voluntad de Dios.

${ }^{5}$ Knight, 8-9. 


\section{Conclusión}

\section{Resumen}

La Educación Adventista nace con una visión profética. Su objetivo principal es preparar a los alumnos para la crisis final y para el reino eterno de Cristo. En ella, los hijos de adventistas conocerán mejor al Cristo de la Biblia, tendrán una profesión de fe bíblica, serán discipulados para proclamar la verdad presente y serán preparados para la eternidad.

Cada institución ha sido llamada para discipular y preparar misioneros que proclamen los Mensajes de los tres ángeles.

\section{Llamado}

Si deseas que tu hijo continúe relacionándose con Cristo, sea un líder servicial en la iglesia, se prepare para el reino eterno de Cristo y llegue a proclamar los Mensajes de los tres ángeles, te invito a matricularlo en una institución educativa adventista. Una institución educativa adventista es uno de los instrumentos más poderosos que tiene el Espíritu Santo para ayudar a cada menor en su crecimiento cristiano. El Señor nos ayudará a cumplir todas nuestras metas. 